\title{
NO LIMIAR DO EXTRALITERÁRIO: PREFÁCIOS, AD- VERTÊNCIAS E A AUTOCONSTITUIÇÃO DO AUTOR
}

André Luiz Barros da Silva

(UERJ)

\section{RESUMO}

Investigação das relações entre os paratextos (prefácios, “avisos ao leitor" etc.) e a narrativa principal de romancistas do século XVIII francês, em momento de autolegitimação do romance como gênero. Tanto os debates de defesa ou ataque aos romances, quanto a ficcionalização dos prefácios são analisados como índices de uma polêmica cultural de ascensão do romance na modernidade. Três autores brasileiros, em épocas distintas - Machado de Assis, Clarice Lispector e Alberto Mussa - são analisados como herdeiros daqueles debates, sob o aspecto de um jogo complexo entre paratextos e texto principal, bem como entre projeto admitido e autoconstituição da imagem pública do autor, numa contemporaneidade de intensa presença midiática. A herança indica uma continuidade (teórica) entre o momento de ascensão do romance e os desdobramentos posteriores de uma modernidade que manteve a importância desse gênero literário.

PALAVRAS-CHAVE: Teoria da literatura; Romance moderno; Paratextos editoriais; Estatuto da autoria.

Os estudos sobre as inescapáveis tensões que o texto literário estabelece com o âmbito dos discursos extraliterários, tanto por suas características intrínsecas quanto pelo contexto cultural sempre mutável que o circunda, incidem sobre dois aspectos a nosso ver cruciais para se entender o próprio ao fenômeno da literatura. De um lado, estabelece-se necessariamente uma negociação ou um diálogo, que nos primórdios da legitimação do romance como gênero era a uma só vez tenso e discreto, já que o desnível entre o prestígio da cultura da retórica e das belles-lettres, dominantes à época, nem sempre permitia que a defesa do romance se desse de forma explícita ou frontal. De outro lado, há toda uma reconfiguração dos modos pelos quais o 
autor se apresenta no espaço público, espaço esse obviamente pautado pelos outros discursos, extraliterários.

Para analisar ambos os domínios a investigação dos prefácios, das "advertências", dos “avisos ao leitor" ou mesmo das epígrafes, ou seja, os textos que antecedem a narrativa de ficção propriamente dito, mostra-se bastante frutífera, já que nesse espaço discursivo são postos em pauta, explícita ou implicitamente, os temas da citada negociação entre os defensores do romance e as outras instâncias sociais, resistentes a tal defesa. Um mergulho nesses paratextos, ${ }^{1}$ no século XVIII francês, certamente ajuda a investigar uma dimensão importante para a própria modernidade, vista pelo ângulo do campo literário. E o retorno a autores recentes ou contemporâneos só faz iluminar o fato de que essa questão - por assim dizer, trans-histórica - guarda sua importância teórica sobre tal modernidade, até hoje.

Nos estudos a respeito há a tendência a ver tais prefácios ou "avisos ao leitor" como metanarrativa, já que se trata de discurso sobre a narrativa no qual surge uma subnarrativa, ficcionalizada, sobre o modo como os originais do que se lerá a seguir chegou ao editor. Trata-se de uma das formas do que Gérard Genette chama de "narrativa de segundo grau". Entre vários exemplos, destaquemos o conciso "Avis au lecteur" do romance Mémoires du comte de Comminge, grande sucesso de Madame de Tencin (1735): "Este manuscrito foi encontrado entre os papéis de um homem depois de sua morte. Notamos que ele deu nomes falsos a seus personagens..." (TENCIN, 1996, p. 19). Quarenta e sete anos depois, o jogo de vai-e-volta entre o "Avis de l'éditeur" e o "Préface du redacteur" do célebre Les liaisons dangereuses, de Choderlos de Laclos, é bem mais intrincado. No primeiro, o suposto editor logo avisa: "Julgamos de nosso dever prevenir o público de que, apesar do título desta obra e do que dela diz o redator em seu prefácio, não garantimos a autenticidade da coletânea, e temos mesmo fortes razões para pensar que se trata apenas de um romance" (LACLOS, 1990, p. 9). No segundo, lê-se que o editor foi "encarregado de organizá-las [as cartas, já que é romance epistolar] pelas pessoas a quem fora ter (a qui elle était parvenue)", só tendo pedido a eles "como paga, a permissão de podar tudo o que me parecesse perfeitamente inútil”.

Como se vê, trata-se de uma narrativa ficcional a respeito da origem da narrativa ficcional que se lerá na sequência. J. Sramek chamou atenção para o fato de que o prefIxo "meta", em metanarrativa, acaba se referindo a dois fenômenos distintos. De um lado há o que Genette indica como discurso incrustado na própria narrativa, criando um domínio "de segundo grau" - daí 
o exemplo que ele dá, o trecho da Odisseia em que Ulisses relata suas façanhas até aquele momento: “...a narrativa em segundo grau é uma forma que remonta às próprias origens da narração épica, já que os cantos IX a XII da Odisseia (...) são consagrados à narrativa feita por Ulisses diante da assembleia dos Feácios" (GENETTE, 1973, p. 241). De outro lado, no entanto, haveria o modelo de um texto segundo que se refere, de fora, a um texto primeiro, ambos sendo narrativas ficcionais. "Um discurso (uma linguagem, um texto, uma narrativa) pode se referir a si mesmo, tornar-se objeto de sua própria reflexão, ou então pode 'gerar' outro discurso (uma linguagem, um texto, uma narrativa) que o tom por objeto", escreve E. Zawisza a respeito da bipartição sugerida por Sramek. Recorde-se que, por seu lado, Abastado lembra que esse texto gerado pelo primeiro só pode se compor no momento posterior (après-coup), como comentário ao primeiro, o que sem dúvida o aproxima do próprio texto da crítica literária (ZAWISZA, 2013, p 76). Obviamente, seja em meio ao próprio antetexto ficcionalizado, seja em prefácios ou "advertências ao leitor" de real informação sobre a obra que se lerá, a argumentação em prol da própria existência ou da pertinência cultural do que se lerá em seguida é um comentário metanarrativo com claros objetivos reflexivos ou críticos sobre o gênero (conto ou romance) ou sobre a literatura como domínio diverso daquele que as belles-lettres e a retórica imaginavam para si próprias. E isso mesmo que sem a consciência explícita dos temas em questão. Tratar-se-ia de um bom exemplo de Zeitgeist, no sentido de absorção ou reprodução, mais ou menos inconsciente, das questões circulantes na cultura do momento pelo autor, tenha ou não ele vocação teórica ou gosto pela polêmica.

É o caso de Claude Crébillon, cujo pai, Prosper Jolyot de Crébillon, no papel de prestigiado autor de tragédias na linhagem de Corneille e Racine (mas sem o brilhantismo deles), esteve envolvido em diatribe com o Voltaire, jovem ambicioso que queria estabelecer fama no teatro parisiense, de corte clássico, dos anos 1710-20. Claude prefacia seu (inacabado) romance Les égarements du cœur et de l'esprit (1735) - cujo estilo dista bastante da seriedade do pai ou de Racine - citando Horácio:

O homem que escreve não deve ter senão dois alvos: o útil e o prazeroso. Poucos autores conseguem reuni-los. O que instruiu, ou negligencia o prazer, ou não tem talento para tanto; e o que diverte não tem força o bastante para instruir: o que faz necessariamente com que um seja sempre seco, e que o outro seja sempre frívolo. (TROUSSON, 1993, p. 19)

$\mathrm{Na}$ sequência, o autor aproxima o aspecto educativo que o romance 
pode oferecer ao trabalho da sátira (a latina satura) de ataque ao vício como objetivo sério (edificante) do escrito cômico: "O romance (...) seria talvez, entre todos os gêneros, aquele que se poderia tornar mais útil (...) se, em vez de preenchê-lo com situações tenebrosas e forçadas (...), o tornássemos, como a comédia, o quadro da vida humana, e que censurássemos nele os vícios e os ridículos" (TROUSSON, op. cit.). Mais grosseiro como comentário crítico, o "Avertissement" do conto longo Les confessions $d u$ Comte de $e^{* * *}$, de Charles Duclos (1741), oferece, no entanto, uma reflexão antecipadora sobre o exemplo romanesco como particular de um universal a que o leitor terá de aproximá-lo ou contrapô-lo:

Como cada vício e cada ridículo são comuns a várias pessoas, é impossível retratar caracteres sem que se encontre neles alguns traços de semelhança com aqueles mesmos que não foram alvo dele [desse retrato]. Assim, não se duvida de modo nenhum que estas memórias ocasionem comparações (applications) que o autor nunca imaginou. (TROUSSON, 1993, p. 179).

A ideia por trás do termo "applications" é a de ligação ou identificação direta entre o personagem e pessoas reais. Note-se que o pequeno trecho inclui duas ambiguidades. A primeira, apontada, é a repreensão à application, que soa como denegação de um incentivo a fazer o que no fundo é inevitável diante de qualquer narrativa, ficcional ou baseada em fatos reais: aproximar as ações de seus personagens das ações de outras pessoas; por assim dizer, de carne e osso. A segunda ambiguidade está no simples uso da palavra "mémoires": o "Advertissement" antecipa a ficção, tendo sido redigida pelo narrador de "memórias" que, apesar do nome, são inventadas.

A voga de se compor o que aqui podemos chamar de labirinto pré-narrativo vinha de décadas passadas. Tanto que, ainda em 1704, o autor das Mémoires du Comte de Gramont, Antoine Hamilton, escritas a partir de dados reais mas sem a mínima fidelidade a eles, inicia seu romance-memória elogiando aqueles que leem por puro prazer, o que lhe permite desrespeitar a cronologia: “...a ordem do tempo, ou a disposição dos fatos, que custam muito ao escritor e não divertem em nada o leitor, não me embaraçarão de modo nenhum no arranjo [dos acontecimentos] dessas Memórias" (ÉTIEMBLE, 1960, p. 29). Se as memórias constituíam um gênero de imenso sucesso em um momento que, como destaca Étiemble, a aristocracia ainda tinha uma imagem positiva e sem autocríticas de sua própria posição de "Grandes" do reino e, portanto, merecedores dos louros e das homenagens por conta de vidas que deveriam ser admiradas pelos pares e pelo vulgo em geral, Hamil- 
ton usará o gênero de autoengrandecimento para narrar passagens picantes e libertinas, assumindo o fato (real) de que esse submundo, matéria da bateria de rumores e boatos ligados aos bastidores da Corte, era alvo de grande interesse do público, ávido não apenas por grandes atos morais, administrativos ou militares, mas também por pequenos atos erótico-amorosos.

$\mathrm{Na}$ verdade, a reação dos académiciens à nova (e, para eles, perigosa) moda das narrativas que tinham tais pequenos interesses erótico-amorosos (ou apenas os amorosos, na versão mais palatável, ou não libertina, do novo gênero literário) já começara desde a famosa Querelle des Anciens et des Modernes (Querela entre os Antigos e os Modernos), ainda nos anos 166566. A polêmica tem no antetexto do Dialogue des Héros du roman, de Boileau, um bom exemplo para os fins de nossa investigação. No Discours sur le Dialogue suivant, prefácio àquele texto dialógico-satírico, Boileau deixa clara sua posição, localizando no sucesso da Astrée, de Honoré d'Urfé, o início da febre que ele quer combater. Como se sabe, trata-se de romance em que o tema amoroso hiper-idealizado não deixa espaço para nenhuma "baixeza" libertina. Lê-se no Discours... de Boileau:

O Diálogo, que se oferece aqui ao Público, foi composto na ocasião dessa prodigiosa miríade de Romances que apareceram perto da metade do Século precedente, e sobre os quais eis aqui poucas palavras sobre sua origem. Honoré D'Urfé, homem de excelente qualidade, da região de Lyon, e bastante inclinado ao amor, querendo fazer valer um grande número de Versos que tinha composto para suas Amadas, e reunir em um volume várias aventuras amorosas que lhe tinham acontecido, imaginou uma invenção bastante agradável. Fingiu que na Floresta (...) existira, no tempo de nossos primeiros reis, um Grupo de Pastores e Pastoras que viviam nas margens do Rio de Lignon e que (...) por simples diversão e só por prazer não deixavam de eles mesmos apascentarem seus rebanhos. Todos esses Pastores e todas essas Pastoras, vivendo numa imensa ociosidade, o Amor, como se pode imaginar, e como ele mesmo conta, em nada tardou a vir inquietá-los e produziu uma grande quantidade de acontecimentos consideráveis. (...) Compôs assim um Romance, que lhe trouxe muita reputação (...); embora a moral nele fosse bastante viciosa, já que se incentivava ali apenas o Amor e a doçura (...). O grande sucesso desse Romance tanto abrasou os Belos-Espíritos de então que eles fizeram, imitando-o, uma grande quantidade de obras semelhantes, entre as quais houve as que atingiram dez ou doze volumes. E passou-se algum tempo como que num transbordamento sobre o Parnaso. Elogiou-se sobretudo os de Gomberville, de La Calpenedre, de Des Marais e de Scuderi. ${ }^{2}$ Mas esses Imitadores se esforçaram, de maneira inoportuna, para enriquecer seu Original, e pretendendo enobrecer seus 
Herois, caíram, a meu ver, numa enorme puerilidade. Pois em vez de tomar por Heróis, como ele fez, os Pastores ocupados com o único objetivo de ganhar o coração de suas Amadas, escolheram, para lhes dar essa estranha ocupação, não somente príncipes e reis, mas os mais famosos Capitães da Antiguidade, retratando-os plenos do mesmo espírito desses Pastores; tendo feito, a exemplo deles, uma espécie de voto de nunca falar nem ouvir senão do Amor. (BOILEAU, 1966, 443-446)

Textos como esse, de um prócer da Academia, do partido dos Anciens, nos anos 1660, são os ancestrais de outros do século seguinte, como as Conversas sobre os romances (Entretiens sur les romans), de Armand-Pierre Jacquin, de 1755. O tema do amor ressurge ligado ao da ilusão. A ficção e a ilusão - termos ligados à ideia de verossimilhança - ressurgem em sua negatividade, dado que não se adequam a modelos tradicionais. Rumo à ilusão dos "realismos" da modernidade, o texto demonstra o medo e o rechaço ao avanço de um tipo de narrativa cuja moral não é controlável pela hierarquização dos temas típica das obras-modelos da Grécia antiga. A moralidade surge como argumento mais direto para um desconforto diante do incontrolável da nova verossimilhança, que inclui o amor como o tema sedutor por excelência, mas que também afasta "os jovens do estudo das belas-letras", como se lê na citação abaixo. A pedido da Condessa, cujo sobrinho é leitor de "maus romances", o Abade, que não admite nem os "bons", argumenta em momento em que o prestígio do gênero romanesco já parece irresistível:

Encarregas-me, Madame, de uma tarefa bem crítica, solicitando minha opinião sobre essas obras, que se vê todos os dias se multiplicarem: elas encontram (...) tantos aprovadores quantos homens há; é portanto entrar num processo contra o gênero humano, atacá-los. (...) não posso evitar de proibir à juventude essas obras que consideras bons. Parecem-lhes tais tão somente porque escondem com mais cuidado um veneno, que sábias reflexões mantidas por um coração pleno de retidão e de inocência tornaram ineficaz em ti; mas quantas almas como as tua se encontram por aí? (...) Não ignoro que há Romancistas como Poetas, e que a imaginação muito liberta os leva frequentemente além dos limites que sem dúvida prescreveram a si mesmos. Entretanto, embora eu estime todos os que se distinguem por seus talentos, confesso que a força da verdade e a pureza da moral terão para mim sempre um charme mais poderoso. (...) convenho que os Ségrais, os M..., os C... merecem elogios; mas também não posso desconvir que esses escritores deveriam empregar com mais utilidade sua perigosa facilidade de escrever. Para ti, Senhor, faça-me a graça de crer que não tenho outro motivo senão o de apartar de teu espírito as ideias 
quiméricas, que afastam todos os dias os jovens do estudo das belas-letras; e de teu coração, as pinturas capazes de surpreender os sábios, e de fazer corar a virtude.

O Cavalheiro. Já começas, Senhor, a me inspirar desconfiança por um pendor secreto, que me fazia adorar essas leituras sedutoras demais.

A Condessa. Fazes milagres, Sr. Abade; convertes as pessoas antes de pregar para elas. (JACQUIN, 1755, p. 21)

Se o debate crítico, desde meados do século anterior, o XVII, misturava conservadorismo moral e pavor da desvalorização do cânone beletrístico, prefácios e "avisos ao leitor" dos romances da época tentavam burlar ambos os ataques conservadores por meio do ardil labiríntico da metanarrativa que isenta o autor de qualquer culpa. Romance paradigmático da transposição das memórias para o gênero não-elevado, La Vie de Marianne, sucesso de Marivaux a partir de 1731, traz, em seu "Avertissement", o topos paratextual do "manuscrit trouvé" (manuscrito encontrado), ou seja, o original achado em algum local, ou entregue por alguém, cuja veracidade fica, assim, suposta, mas a cuja origem não se tem mais acesso (HERMAN, KOZUL, KREMER, p. 150). O início do romance aponta para uma estratégia usada para burlar a patrulha que não aceita o estabelecimento ou a legitimação de um espaço de liberdade romanesca onde se possa integrar, mimetizando-os, os discursos da sociedade que escapavam daqueles já codificados nas obras beletrísticas. Nesse sentido, o início de La Vie de Marianne permite acesso a uma estratégia de alto teor de ambiguidade - a simulação de veracidade do "manuscrito encontrado". O expediente - dir-se-ia, labiríntico, já que se trata de criar uma narrativa tópica (tornado mesmo um lugar-comum e, portanto, como mostra J. Herman de forma percuciente, modificando sua própria função para os leitores já acostumados com o romance, que reconheciam o topos precisamente como um topos) pela qual o manuscrito passou de mão em mão até chegar ao leitor atual - pode ser visto à luz de ataques como os de Jacquin, segundo os quais as memórias verossímeis que compõem o romance não podiam atrair o mesmo grau de interesse de memórias de personalidades célebres baseadas em sua experiência real. Por outro lado, vê-se o modo como vários romances do século XVIII na verdade se desviam, sem tratar diretamente (talvez para evitar as críticas que os deslegitimavam), da questão da própria ficcionalidade - aquilo que N. Kremer aponta como os três níveis entrelaçados da verossimilhança no romance do século XVIII: as verossimilhanças ontológica, poética e retórica. Na verdade, ao tornar ambígua e indecidível a questão da 
ficcionalidade do que se vai ler (o que, no mundo do século XIX em diante se tornará impossível, dada a institucionalização na Europa burguesa do mercado editorial e o desaparecimento do amplo mercado de livros clandestinos), a narrativa joga num limiar semi-institucionalizado no qual a ficção (a nova verossimilhança) não quer se assumir como tal, embora seja assumida para leitores que conheçam o autor e suas estratégias. Vamos ao trecho:

Como se poderia supor que esta história fora feita especificamente para divertir o público, creio dever advertir que a recebi, eu mesmo, de um amigo que de fato a encontrou, como ele o diz logo adiante, e que não lhe adicionei nada a não ser retoques em algumas passagens confusas e negligenciadas demais. O que há de verdade é que, se fosse uma história simplesmente imaginada, muito provavelmente não teria a forma que tem. Marianne nela não faria nem tão longas, nem tão frequentes reflexões: haveria mais fatos e menos moral; em uma palavra, não se conformaria ao gosto geral de hoje em dia que, em um livro desse gênero, não é favorável às coisas um pouco refletidas e razoáveis. (MARIVAUX, 1997, p. 57)

A "Primeira parte", que se segue, ainda insiste na narrativa em segundo grau: Há seis meses comprei uma casa de campo a alguns quilômetros de Rennes (...). No armário colocado em um espaço recuado numa parede, encontrou-se um manuscrito em vários cadernos contendo a história que se vai ler, com jeito de escrita de mulher. Entregaram-me; li-os com dois de meus amigos que estavam em minha casa, e que, a partir daquele dia, não pararam de me dizer que era preciso imprimi-lo: quero de bom grado, ainda mais porque essa história não interessa a ninguém. [No sentido de não existirem pessoas vivas que conheceram os personagens supostamente reais da história narrada] (Idem)

Percebe-se que a imbricação entre o antetexto e a narrativa transcorre como se a ficção estivesse sendo recalcada enquanto tal. Trata-se, obviamente, de escaramuça para fazer crescer um encanto que, com o aparecimento de vários romances com tal tipo de ambiguidade prefacial (os dois exemplos mais famosos no século, algumas décadas depois do aparecimento do modelo de Marivaux, continuam sendo Julie ou La Nouvelle Heloïse, de Rousseau, de 1761, e Les liaisons dangereuses, de Choderlos de Laclos, de 1782), começa a se tornar uma nova tradição moderna do romance e, portanto, uma convenção (um topos) que, a partir de certo momento, será reconhecida pelo leitor acostumado com o gênero. O que, é claro, determina o fim da ambiguidade para a maior parte dos leitores, já persuadidos para a aceitação do novo gênero. ${ }^{2}$ 
O que J. Herman, seguindo os passos de Georges May, autor do mítico Le dilemme du roman au XVIIIè siècle, indica ao destacar que: “...É óbvio que a maior parte dos leitores não tinha a ingenuidade de tomar ao pé da letra semelhantes pretensões à autenticidade absoluta" (HERMAN, MOZUL, KREMER, 2008, p. 51), é simplesmente que talvez o alvo retórico de tais paratextos fosse exatamente a sensação de suspensão do juízo (ou da ambiguidade) praticada apenas pelos "já iniciados", diante de um texto que simula autenticidade para leitores não avisados. Numa cultura pautada pelo pertencimento a grupos de prestígio, como era o caso no Antigo Regime, a persiflage (ridicularização do outro, excluído do grupo no aqui-agora por não conhecimento de certos códigos) que tal desconhecimento permitia não pode ser descartada como aspecto prazeroso experimentado pelos que conheciam o código do prefácio ilusório.

Por outro lado, o manuscrito se encaixa propriamente no gênero das memórias, e Marianne (que não revela seu sobrenome nem no subtítulo, Ou les Aventures de Madame la comtesse de ${ }^{* * *}$, mas indica, sim, sua origem nobre) desenvolve sua narrativa em primeira pessoa sabendo dos desdobramentos finais de sua própria história, como sempre acontece no caso de memórias - e não ocorre no caso de cartas, que vão sendo escritas e lidas (pelos personagens e/ou pelos leitores reais) à medida que a trama se desenrola, sem conhecimento prévio de sua conclusão. O que não impediu que o romance mais bem-sucedido de Marivaux tenha servido como uma espécie de modelo sensible para o inglês Samuel Richardson, autor de Pamela e Clarissa, entre outros sucessos do século XVIII no campo do romance epistolar.

***

Como se percebe pelos textos e autores citados, as polêmicas críticas (as tensões) em que os autores da época se envolviam, quisessem, tivessem consciência ou não, levaram-nos também a, por assim dizer, repensarem a forma como sua função (de autoria) apresentava-se ou subtraía-se em meio aos prefácios e suas metanarrativas. Gostaríamos, agora - com a concisão a que obriga o presente ensaio -, de projetar algumas descobertas relacionadas aos séculos XVII e XVIII franceses em três momentos do romance brasileiro. O intuito é o de mostrar como a investigação é capaz de revelar alguns alicerces do gênero até hoje crucial para a literatura, passados tantos séculos de modernidades (e pós-modernidades, se se quiser) justapostas temporalmente. 
Se Machado de Assis propõe seu labirinto singular ao ligar as "Advertências" de seus dois últimos romances, Esaú e Jacó e Memorial de Aires, em época de amadurecimento do romance no país, com o salto de complexidade oferecido por sua obra, o século XX será muito mais pautado pelas epígrafes, uma espécie de texto a anteceder a narrativa principal cujo teor de mistério ou de virtual ambiguidade poética será muito maior do que a também clara função de inscrever a obra na tradição canônica (ou nem tanto). Queremos, portanto, partir da constatação do uso por parte de Machado daquele mesmo expediente dos romances do século XVIII, agora - como outrora - com intuitos de multiplicar os níveis metanarrativos típicos do autor, para pensar como um autor brasileiro contemporâneo - Alberto Mussa - recorre ao mesmo expediente em momento cultural totalmente diverso.

É conhecido o modo como Machado de Assis se mostra discreto em relação a sua atuação pública. Por outro lado, um momento em que o texto - seja um gênero já tornado mais denso, como o romance, seja um gênero mais ágil e leve, como a crônica - falava pelo autor, no sentido de constituir um anteparo a sua atuação como homem público, bem como a suas opiniões pessoais. Se nas crônicas, como no caso da série Bons dias!, publicada no jornal Gazeta de Notícias entre 1888 e 1889, Machado passa a criar narradores, personagens e enredos francamente satíricos que lhe permitiam subtrair o que seriam opiniões pessoais em prol de narrativas críticas e cômicas sobre o contexto político e social, romances e contos seguem pelo mesmo caminho. Na verdade, como se sabe, a narrativa em segundo grau já era exercida havia algumas décadas por um dos modelos de Machado, o José de Alencar romancista, em seu próprio nome, como no prefácio a Senhora, ou com iniciais misteriosas (fictícias), como o G.M. de Luciola. Político profissional e muito mais afeito a acalorados debates, Alencar era dado a criar pseudônimos polêmicos, como o primeiro e mais famoso deles, o Ig., oriundo da polêmica com Gonçalves de Magalhães, em 1856. No caso de Machado, sua extrema discrição pessoal, relatada por vários contemporâneos, levava-o ao gosto dos anteparos a alguma (suposta) subjetividade una e autêntica (uma definição de corte romântico bastante comum como pressuposto acrítico no meio literário, como se sabe). A intensidade com que, em seu discurso na Sorbonne em 1909, "Machado de Assis et son œuvre littéraire", Oliveira Lima deplora tal discrição, bem como o fato de Machado não ter deixado memórias não-ficcionais, mostra bem a obsessão biografista da época, que Machado soube burlar com galhardia. O jogo labiríntico das duas "Advertências", a de Esaú 
e Jacó, sem assinatura, a de Memorial de Aires, assinada "M. de A.", ambas ficcionalizando um Conselheiro Aires - uma espécie de personagem alegórico da velhice do próprio Machado, por assim dizer - que teria deixado um baú de cadernos manuscritos. $\mathrm{O}$ topos do manuscrito legado por um morto serve para afastar a criatura do criador, abrindo um vazio de afastamento típico de autor que já teria escapado da automitificação romântica do eu, rumo à ideia de subtração ou neutralidade do eu no campo da escrita literária - teorizada por, entre muitos outros, um Maurice Blanchot em seu Livro por vir (1959).

Apenas citemos de passagem essa verdadeira implosão metanarrativa do eu que constitui o romance $A$ hora da estrela, de Clarice Lispector (1977). Em momento cultural de franco convívio com os meios de comunicação de massa, em que a própria Clarice trabalhou como jornalista - e não apenas como cronista a comentar fatos do noticiário (com seriedade poética e autossubjetivação narrativa típicas da autora), como foi o caso da crônica "Mineirinho", em que o assassinato do bandido José Miranda Rosa, o Mineirinho, em 1962, deflagrou a escrita de uma crônica em que se pode ler, por exemplo: "É, suponho que é em mim, como um dos representantes de nós, que devo procurar por que está doendo a morte de um facínora. E por que é que mais me adianta contar os treze tiros que mataram Mineirinho do que os seus crimes". Em A hora da estrela, o narrador, Rodrigo S.M., surge já em pleno jogo labiríntico da "Dedicatória do autor", cujo subtítulo irônico e deliberadamente ingênuo já diz tudo: "(Na verdade, Clarice Lispector)". Entre os doze títulos do romance estão, por exemplo, "Eu não posso fazer nada" ou "A culpa é minha"; títulos esses claramente ligados à consciência doída do narrador diante do simples fato de estar desfiando o enredo de precariedades, materiais ou subjetivas, da protagonista Macabéia. A hora da estrela é, a nosso ver, uma obra que deixa bem claro o jogo que um autor dos anos 1970, como Clarice, pode criar a partir de antetextos. Jogo esse que dinamiza, de forma tensa e múltipla, por um lado, um desdobramento subjetivo que a escrita do romance permite e, por outro, a imagem (labiríntica) que a autora produz de si mesma no espaço público, rebatida ainda na complexa subjetivação da ética interpessoal diante de personagens (ou mesmo pessoas reais) de classes baixas.

Por fim, percebe-se em um autor como Alberto Mussa uma espécie própria de jogo singular com prefácios e "advertências ao leitor" em uma espécie de meio-termo entre a subtração de si típica de Machado e o da (auto) subjetivação do narrador, bem como da figura a um só tempo afastada e próxima da autora, em Clarice. Obviamente, se cada caso deve ser estudado 
tendo como pano de fundo culturas e épocas bem diversas, a verdade é que a comparação e a "longa duração" podem jogar luz sobre as formas que tomam as transformações culturais e os ambientes de subjetivação a elas associados. $\mathrm{Na}$ "Advertência" de seu último romance, A primeira história do mundo (2014), Mussa se coloca como autor de "projeto absurdo" iniciado em 1999: a composição de cinco novelas (no sentido de romances) policiais tendo a história do Rio de Janeiro como cenário. Já que no caso desse romance, o caso policial ocorreu em 1567, quando não havia a figura profissional do investigador, Mussa propõe que o papel desse tipo de personagem será exercido pelo próprio autor, a reunir os pontos não documentados do ocorrido. Mas o jogo ficcional tem outra dobra: o autor propõe dividir com os leitores "a fascinante tarefa de reproduzir a investigação, de examinar os dados do processo, bem como outros documentos que iluminem o caráter das personagens envolvidos" (MUSSA, 2014, p. 8). A proposta de fato se realiza narrativamente: ao longo de todo o romance há intervenções do narrador (assumido como autor). Exemplos: "Insisto nesse tema das portas e ladeiras porque o leitor de novelas policiais deve notar sobretudo os pormenores" (Idem, p. 37); "se estamos hoje (eu e os leitores) refazendo uma investigação de mais de quatro séculos" (Idem, p. 52); "Tudo isso é possível. Mas quero compartilhar com o leitor uma hipótese engenhosa" (Idem, p. 53). Há digressões mais longas, em que o autor compara sua trama até mesmo a enredos de cinema: "A ficção policial vulgar e especialmente a cinematografia norte-americana têm hoje preferido enigmas muito elaborados" (Idem, p. 51).

Partícipe de um momento em que o escritor pode surgir na TV, nos jornais ou na internet, explicando, em várias ocasiões e em seu próprio nome, suas intenções ou seus projetos literários, tanto Clarice quanto Mussa parecem usar o labirinto que surge entre o antetexto e a narrativa principal para propor um jogo de complexificação lúdica de modo a burlar as figurações por demais fixas que o público pode fazer do autor - a partir de pressupostos sociais comumente compartilhados, por exemplo, o da unicidade da vontade ou da intenção autoral. Desde que o New Criticism decretou, ainda nos anos 1940, a falácia da intenção do autor muita água já rolou e, obviamente, tanto Clarice quanto Mussa parecem construir um jogo labiríntico que tem de incluir, necessariamente, o plano do que as próprias mídias ajudam a construir como figuração (institucionalizada e tecnologizada) da imagem do escritor. Com efeito, Mussa costuma colecionar tanto prefácios ou posfácios quanto entrevistas em que explica seus projetos literários. É o caso de Meu destino é ser onça, livro híbrido em que ele compõe, ficcionalmente, uma cosmogonia 
tupi coerente e linear a partir dos vários fragmentos mitológicos recolhidos por estudiosos. A falta de limite entre literatura e ensaio não surpreende em um admirador confesso de Jorge Luís Borges. Por outro lado, é bem interessante o modo como o autor cria um enredo (que não podemos saber até que ponto é inventado, posto que mesmo em entrevistas, a um criador é consentido que jogue com a verossimilhança...) para apresentar seu próprio projeto:

Por isso - porque quis fazer literatura - não me limitei a traduzir e anotar a versão francesa do frade. Produzi um texto novo, em português, que corresponde a um possível original tupi, no nível estritamente teórico do seu encadeamento lógico. Pessoas que não denunciarei me acusaram de fraude. Porque o texto tupi - que eu dizia ter restaurado - nunca tinha sido escrito, nunca tinha sido texto, na estrita acepção do termo. (MUSSA, 2009, p. 27).

Existiriam mesmo tais “pessoas que não denunciarei”? Não podemos confirmar, já que se trata de jogo que remete o livro ao fora-do-livro, ao espaço público e midiático (hoje termos sinônimos) de forma lúdica. Nesse caso a "mentira" é bem-vinda: trata-se de complexificar a relação do público com o eu do autor.

Em entrevista divulgada pelo próprio portal da editora do livro, Mussa explica, desdobrando seu jogo: "Não quero que o livro seja tomado por um ensaio acadêmico ou científico. Nem por uma obra de pura ficção. Quis criar o 'mito que poderia ter sido', o 'mito baseado em mitos reais'. É onde reside a literariedade do texto". Note-se que a fórmula "mito baseado em mitos reais" tem alto teor de autoironia, desfeita na seriedade - inclusive teórica - da frase seguinte.

Dos primórdios seiscentistas e setecentistas franceses aos tempos atuais, a construção labiríntica que transborda da narrativa inventada para os prefácios e demais antetextos (muitas vezes também inventados, mas nem sempre), serve de apoio ao jogo do autor e do livro com o espaço que os circunda, e cujas lógicas de apreensão do que é admissível como jogo lúdico, bem como as concepções, conscientes ou não, da subjetividade individual (do eu), são diversas do que se dá dentro do texto e do livro. Nesse limiar se decidem as vias por onde o romance mantém e/ou transforma seus modos atuação nos domínios exteriores ao estritamente literário. 


\section{ABSTRACT}

Inquiry about the relations between the paratexts (prefaces, "foreword to the reader" etc.) and the main narrative of French novelists of the XVIIIth century, in a moment of auto-legitimation of the novel as genre. The debates pro and against the novels and the ficcionalization of forewords will be analyzed as signs of a cultural polemic of rise of the novel in modernity. Three Brazilian authors - Machado de Assis, Clarice Lispector and Alberto Mussa - will be analyzed as heirs of these debates, under the aspect of a complex play between paratexts and main narratives, and between admited projects and the auto-constitution of the public image by the author, in a contemporary time of intense midiatic presence. The heritage shows a (theoretical) continuity between the moment of the rise of novels and the ulteriors deployements of a modernity that has maintained the importance of the novel as genre. KEYWORDS: Theory of literature; Modern novel; Paratexts, Statute od authorship.

\section{REFERÊNCIAS}

BOILEAU. Euvres complètes. Paris: Gallimard, 1966.

ÉTIEMBLE. Romanciers du XVIIIè siècle. Paris: Gallimard,1960.

GENETTE, Gérard. Figures III. Paris: Seuil, 1973.

GENETTE, Gérard. Paratextos editoriais. São Paulo, Ateliê, 2009.

HERMAN, J., KOZUL, M., KREMER, N. Le roman véritable. Oxford: Voltaire Foundation, 2008.

JACQUIN, A.-P. Entretiens sur les Romans. Paris: Chez Duchesne, Libraire, 1755.

LACLOS, Choderlos de. As ligações perigosas. São Paulo: Ed. Anima, s/d.

MARIVAUX. La Vie de Marianne. Paris: Gallimard, 1997.

MUSSA, Alberto. A primeira história do mundo. Rio de Janeiro: Editora Record, 2014.

MUSSA, Alberto. Meu destino é ser onça. Rio de Janeiro: Editora Record, 2009.

MUSSA, Alberto. Entrevista - Meu destino é ser onça. Disponível em: http://www. record.com.br/ autorentrevista.asp?id_autor $=31 \& \mathrm{id}$ entrevista $=24$ 
TENCIN, Madame de. Mémoires du comte de Comminge. Paris: Les Éditions Desjonquères, 1996.

TROUSSON, Raymond (ed.). Romans libertins du XVIIIè siècle. Paris: Robert Laffont, 1993.

ZAWISZA, Elisabeth. L'âge d'or du péritexte. Paris: Hermann, 2013.

\section{NOTAS}

${ }^{1}$ A denominação é de Gérard Genette e indica textos anteriores (antetextos) ou posteriores à narrativa ficcional propriamente dita. (GENETTE, 2009).

${ }^{2}$ Nesse sentido, é interessante notar que os prefácios e "avis au lecteur" do século XVIII consituem uma espécie de prática textual mediadora de transição, já que se pode dizer que diminuem muito em quantidade no século XIX - em especial durante a voga realista-naturalista, quando se verá, no máximo, prefácios críticos, como o famoso de Zola em Thérèse Raquin, mas quase nunca metanarrativos. Como se sabe, há também gêneros romanescos de transição, os mais conhecidos talvez sendo o epistolar (não desaparecem, mas sua quantidade decresce muito) e a literatura de libertinagem (que tende a desaparecer depois do fenômeno Sade). Seria interessante determo-nos, em outra ocasião, no porquê da emergência e do desaparecimento de tais práticas ou (sub)gêneros. O ponto de partida, a nosso ver obrigatório, é que eles têm a ver com uma premência ligada ao momento de ascensão e de autolegitimação do romance.

Recebido em: 31 de maio de 2015

Aceito em: 20 de agosto de 2015 